\title{
Factors Associated with Initiation of Advance Care Planning in Dementia: A Systematic Review
}

Jenny T. van der Steen ${ }^{\mathrm{a}, *}$, Mirjam C. van Soest-Poortvliet ${ }^{\mathrm{a}}$, Meertje Hallie-Heierman ${ }^{\mathrm{a}, 1}$, Bregje D. Onwuteaka-Philipsen ${ }^{\mathrm{b}}$, Luc Deliens ${ }^{\mathrm{b}, \mathrm{c}}$, Marike E. de Boer ${ }^{\mathrm{a}}$, Lieve Van den Block ${ }^{\mathrm{c}}$, Nicole van Uden ${ }^{\mathrm{c}, 2}$, Cees M.P.M. Hertogh ${ }^{\mathrm{a}}$ and Henrica C.W. de Vet ${ }^{\mathrm{d}}$

${ }^{\mathrm{a}}$ Department of General Practice \& Elderly Care Medicine, EMGO Institute for Health and Care Research, VU University Medical Center, Amsterdam, The Netherlands

${ }^{\mathrm{b}}$ Department of Public and Occupational Health, EMGO Institute for Health and Care Research, VU University Medical Center, Amsterdam, The Netherlands

${ }^{\mathrm{c}}$ End-of-Life Care Research Group, Vrije Universiteit Brussel \& Ghent University, Vrije Universiteit Brussel (VUB), Brussels, Belgium

${ }^{\mathrm{d}}$ Department of Epidemiology and Biostatistics, EMGO Institute for Health and Care Research, VU University Medical Center, Amsterdam, The Netherlands

Handling Associate Editor: Tania Zieschang

Accepted 20 December 2013

\begin{abstract}
. predict the course of the dementia. of care and health care system factors also affected initiating of ACP. system and personal factors affecting initiation of ACP.

\footnotetext{
${ }^{*}$ Correspondence to: Jenny T. van der Steen, PhD, VU University Medical Center, EMGO Institute for Health and Care Research, Department of General Practice \& Elderly Care Medicine, Van der Boechorststraat 7, 1081 BT Amsterdam, The Netherlands. Tel.: +31 20 4449694; Fax: +31 204448234 ; E-mail: j.vandersteen@ vumc.nl.

${ }^{1}$ Currently: GGZ Friesland, The Netherlands.

${ }^{2}$ Currently: VPTZ Nederland, Bunnik, The Netherlands.
}

Background: Planning ahead may be particularly relevant in dementia considering patients' cognitive decline and difficulty to

Objective: To identify factors associated with initiation of advance care planning (ACP) regarding end-of-life issues in dementia. Methods: Systematic review of the PubMed, Embase, Cinahl, Psychinfo, and Cochrane databases until January 2013. We included articles reporting on empirical research, identifying factors related to initiation of ACP defined as starting a discussion, starting the decision making, or having a documented patient-written advance directive.

Results: Of 4,647 unique articles, we assessed 178 as full-texts, and included 33. Most designs (64\%) were qualitative; $42 \%$ limited to moderate to severe, and $6 \%$ to mild to moderate stages. Perspectives varied: family (33\%), professional caregivers $(24 \%)$, patient (15\%), or multiple (27\%). A variety of factors with complex interplay was involved in initiating ACP. Family factors dominated, with family's initiative or lack of it, and willingness or reluctance to engage in initiating ACP identified in a series of studies. Further, professional caregivers' initiative or lack of it and patient's health status were important factors that facilitated or hindered initiating ACP. Ethnic minority status of those involved and family distance may be barriers. Continuity

Conclusion: Professional caregivers may initiate ACP early if strategies carefully consider timing and family and patient receptiveness or reluctance, and are family and patient-centered. Interventions should address the complexity of interrelated 
Keywords: advance care planning, decision making, dementia, end of life care, hospice care, long-term care, palliative care, professional-family relations, professional-patient relations

\section{INTRODUCTION}

Eliciting health care preferences in an early stage and goal-based care planning may facilitate end-of-life decision making in dementia. These are initial steps of advance care planning (ACP). The PubMed MeSH term defines ACP as "discussions with patients and/or their representatives about the goals and desired direction of the patient's care, particularly end-of-life care, in the event that the patient is or becomes incompetent to make decisions." Others have emphasized ACP as a communication process that occurs over time which is therefore not limited to drawing up of a living will or appointing of a proxy decision maker and a focus on competency [1-4].

There is some evidence on effectiveness of ACP in nursing home residents including but not limited to those with dementia in terms of improvement on process measures. This refers to a better documentation of preferences, changes in health care utilization (decreased hospitalization and increased hospice use), and reduced costs [5-7]. ACP may improve patient and family satisfaction in older hospitalized patients and diminish stress in surviving families [8]. In a pairmatched trial in nursing homes which included families of patients who were incompetent for decision making although not specific to dementia, ACP did not significantly affect patient and family satisfaction with care [9]; more recent work specific to dementia lacked power [10].

In spite of evidence still being sparse, there is a consensus among experts around the globe that planning ahead regarding end-of-life issues can be beneficial in dementia, and that ACP preferably starts early, which maybe around diagnosis, anticipating the patient's cognitive decline [11]. Patients' "ability to imagine" decreases, involving difficulty to imagine scenarios, and increasing lack of taking initiative and decisions [12]. Eliciting patient health care preferences early is also important because families have difficulties distinguishing between their own and patient's preferences [13-15]. Early planning is further justified by the notorious difficulty of predicting prognosis in dementia [16].

Starting around diagnosis, however, may not be common practice; moreover, it may not necessarily and uniformly be the best time to initiate the process of ACP. Around diagnosis, patients and families are already exposed to an abundance of emotional information that needs to be processed, which in itself may need a stepwise, "progressive" disclosure [17, 18]. Patients may wish to live by the day [19] and patients, families, and professional caregivers may not readily talk about end-of-life issues and may lack frameworks that support dialogue. In practice, discussions around end-of-life issues may often not take place or start too late $[5,7]$. The optimal timing of initiating ACP may vary across countries and individuals. For example, Italian families as compared to Dutch families, those with lower education, and caring for older patients were more likely to prefer receiving information on palliative care in dementia before, rather than after nursing home admission [20]. Some may also wish to delegate, postpone, or refuse engaging in ACP. Therefore, we lack evidence to inform an early start of ACP.

For clinical practice, it is important to optimally estimate if and when individuals are open to engage in sensitive dialogues around ACP. From a clinical viewpoint but also from a societal and public heath perspective, it is important to know if certain care structures and processes help trigger the initiation of ACP. To support professional caregivers and optimal design of interventions, we performed a systematic review of the literature to identify factors associated with initiation of ACP. We sought for empirical data on possible barriers and facilitators at different levels (structures and processes of care, and persons) that related to initiation of ACP for end-of-life care in dementia.

\section{METHODS}

\section{Search}

We searched the PubMed, Psychinfo, Cinahl, Embase, and Cochrane databases for articles published up to 10 January 2013 (flow chart in Fig. 1). The search strategy involved the requirement of MeSH terms or words in title or abstract relating to (1) dementia; (2) advance care planning or decision making; (3) at least one of the following four items: setting including institutional and community long-term and hospice care settings; care at the end of life including palliative care; aged 80 and over; relationship such as proxy. An initial search strategy was revised after pilot testing for 


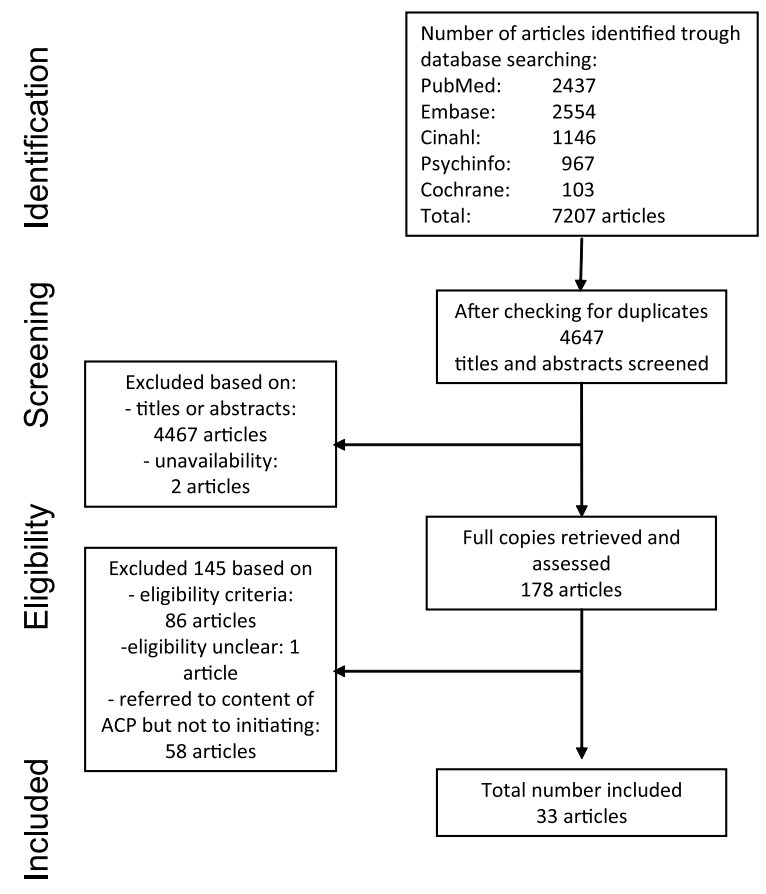

Fig. 1. Identification of relevant articles.

feasibility and for accurate identification of a few key articles on initiating ACP.

\section{Inclusion of articles}

Two team members (MCS-P and MH-H) screened all titles and abstracts for possibly relevant articles. We included articles if the population comprised over $50 \%$ patients with dementia and allowed a lower proportion if presented as an identifiable subset; if written in English, French, German, or Dutch, and if it reported on empirical data (i.e., we excluded articles such as commentaries). We limited to institutional and community long-term care and hospice settings, also including ambulatory care settings. We excluded work from acute care and hospital settings to focus on initiating discussions with favorable possibilities for follow-up, and considering early work that suggested initiating ACP in the hospital might be too late $[21,22]$.

Using a full-text assessment form which was pilot tested, discussed within the team and revised, we abstracted factors related to initiating ACP for end-oflife care in dementia. We defined the initiation of this as: (a) starting a discussion, not necessarily resulting in plans; (b) starting the decision making or a decisionmaking process, i.e., actual planning of care; and (c) having a patient-written, documented advance direc- tive available to professional caregivers (e.g., found in the chart). We included (c) because of its early timing and potential to initiate discussion of the health care preferences indicated in the directive [23]. The advance directive may be a specific living will or a patient authorization of a legal decision maker.

\section{Identifying the factors associated with initiation of $A C P$ and other data abstracted}

Abstracting of factors related to initiating ACP was performed by two researchers completing the fulltext assessment form independently (JTS or NU, and another team member; all authors had a share). Afterwards, all full-text assessments were discussed to reconcile any differences, resulting in combined and agreed-upon completed forms and each included article having been assessed by two to four (usually three) team members.

Other elements independently abstracted with the full-text evaluation included: country, setting, study design (qualitative, quantitative, or mixed-methods), if factors were pre-specified or identified using an explorative design, perspective (e.g., patient or caregiver), and dementia stage.

\section{Data analyses}

Based upon the combined, agreed-upon full-text assessment forms and the original sources, we categorized factors related to initiation of ACP under the main categories structure and process of care, and related to persons (patient, family, or professional caregiver) involved. Subcategories were developed by JTS in consultation with the team, in an iterative process of developing codes, labeling, and some relabeling (e.g., we refined structure of care to include health care system and organization, and context). Further, the final subcategories were verified by MCS-P based on key articles [23-25] that drove several sub classifications and contributed multiple and sometimes difficult to interpret factors.

We analyzed factors related to initiating ACP per article as the unit of analyses. That is, the quantitative or qualitative data of one study may be published in more articles, or different articles may, for example, focus on different phases of ACP. Considering generalizability of the findings, we tabulated factors only if the sub category, whether or not pre-specified, was found in at least two studies, also reporting factors if, for example, found once with a patient, and once with a family. 
We reported separately factors related to the three different outcomes (discussions (a), decision making (b), and written advance directive (c)). We also distinguished between pre-specified, explicitly defined factors such as demographics, versus less clearly defined factors abstracted from explorative, hypotheses raising work. We interpreted the last factors as a facilitator or barrier because this work does not necessarily find that the reciprocal of a facilitator is a barrier and vice versa. For factors that related to structure or process of care, we further examined possible differences between countries considering different health care systems.

\section{RESULTS}

\section{Search result}

The search resulted in 4,647 unique articles of which we retrieved 178 for a full-text assessment (Fig. 1). After excluding ineligible articles, articles referring to a specific direction (content) of decision making, and one article describing a sample with unclear proportion of dementia [26], we included 33 articles that met our inclusion criteria [7, 13, 23-25, 27-54]. These described 29 single studies; two articles per study were available for four studies [7, 13, 24, 28, 33, 38, 42, 53]. The four studies reported on different analyses, subgroups, or phases of the research in each article. Of the 33 included articles 25 were identified in PubMed (76\%), 23 by Embase (70\%), Cinahl and Psychinfo each identified $20(61 \%)$, and Cochrane a single article (3\%, the only ACP intervention study [48]; another tested hypothetical case scenarios [36]). Cinahl found the most in addition to PubMed (7 of 8; Psychinfo 4, Embase 2, Cochrane 0).

Of the 33 articles, 8 (24\%) referred only to (a) starting of a discussion, $12(36 \%)$ only to (b) starting of decision making, and 7 (21\%) to both (Table 1). Five other articles (18\%) referred only to (c) having a patient-written, documented living will, and one article to both (a) and (c).

Most articles (19/33; 58\%) were from the US; only one included comparative data from two countries (Table 1). The first study was published in 1995 [25], and there has been an increase since then, with many articles published in the last few years (12/33 between 2010 and early 2013) with an increasing proportion of non-US studies (three-quarters of these 12 recent articles: five UK and three other countries versus four US). Further, most reports (58\%) limited to long-term care settings. An exclusively qualitative design (64\%) was most common; 33\% had a quantitative design, and one $(3 \%)$ used a mixed qualitative-quantitative design. Ten articles (30\%; eight studies) clearly tested pre-specified factors. Family perspectives $(45 \%$ in total; $33 \%$ exclusively, $12 \%$ combined) were more frequently sought for than views from professional caregivers (24\% exclusively, mostly physicians), or patients $(15 \%)$. In almost half of the articles $(48 \%)$ a dementia stage was specified-mostly moderate to severe dementia (42\%) and infrequently (6\%) mild to moderate dementia.

\section{Pre-specified and non pre-specified factors}

Table 2 shows factors extracted from the 10 articles that tested associations of explicitly pre-specified factors, mostly with (c), having an advance directive, and Table 3 lists the non pre-specified factors. The prespecified factors were abstracted from 10 of the 11 articles with quantitative data only. Demographics were tested most frequently, and findings were insignificant or in opposite directions (combining results in Tables 2 and 3: older patients, gender patient and family, and also family and patient level of education). The serious and (potentially) progressive co-morbid diseases malignancy and congestive heart failure were associated with initiating ACP. Only family ethnic minority status and greater distance (also consistent with disengaged family in Table 3 [25]) were consistently associated with lower chances of initiating ACP.

Table 3 provides a more comprehensive overview of the factors that were not explicitly pre-specified which were abstracted from 23 articles and interpreted as a barrier or facilitator to one or more of the three initiations of ACP outcomes. Only one article addressed written advanced directives, also addressing another outcome which was initiation of discussions within a family context [23]. The authors noted that several of the factors related the initiation of a discussion "were quite similar to those factors that led to creating an advance care directive" [23]. Indeed, most factors related to several outcomes. One understandable pattern was that patients' wishes or willingness to engage, an attitude of planning, and taking initiative were identified as related to (a), initiating discussions (as preceding the making of decisions (b)), and to (c), self-written advance directive.

\section{Interpreting the non pre-specified factors}

We identified slightly more barriers than facilitators, and some factors worked in both directions. We 
Table 1

Typology of the 33 included articles

\begin{tabular}{|c|c|c|}
\hline \multicolumn{2}{|l|}{ Characteristic } & $\begin{array}{l}\% \text { (number of } \\
\text { articles) }\end{array}$ \\
\hline \multicolumn{3}{|c|}{ Initiating outcomes and topics } \\
\hline \multirow[t]{3}{*}{ (a) "Starting discussion" } & Overall & $52 \%(17)$ \\
\hline & $\begin{array}{l}\text { - starting of discussions between patient and/or family, and professional caregiver [ }[27,30,32,33 \text {, } \\
35,39,43,45,46,48,49,52] \text {, includes difficulty or ease of discussions suggestive of initiating } \\
\text { discussions }[36,43]\end{array}$ & $42 \%(14)$ \\
\hline & - starting discussions within family context; not with professional [23]; same study:* [13, 24] & $9 \%(3)$ \\
\hline \multirow{3}{*}{$\begin{array}{l}\text { (b) "Starting decision } \\
\text { making" }\end{array}$} & Overall & $64 \%(21)$ \\
\hline & $\begin{array}{l}\text { - starting of a process of decision making of patient and/or family with professional caregivers } \\
\text { (mostly) }[24,27,31,32,34,37,39,41,43,45,47,50,51,54] \text {; same study: }[33,42] \text {; includes } \\
\text { difficulty or ease of decision making suggestive of initiating decision making }[43,44] \text { and } \\
\text { achieving of consensus with family or among staff }[25,40]\end{array}$ & $61 \%(20)$ \\
\hline & - starting decision making with lawyer/accountant [24] & $3 \%(1)$ \\
\hline $\begin{array}{l}\text { (c) advance directive } \\
\text { Other characteristics }\end{array}$ & - found written advance directive of patient with dementia $[23,29]$; same study: $[7,53]$ and $[28,38]$ & $18 \%(6)$ \\
\hline \multirow{7}{*}{$\begin{array}{l}\text { Countries: number of } \\
\text { publications (single } \\
\text { studies) }\end{array}$} & - US $[23,25,29,31,32,34,35,37,40,43,44,48,50,52,54$; same study: $[13,24]$ and $[28,38]$ & $58 \%(19)$ \\
\hline & - UK $[27,41,45,46,49,51]$ & $18 \%(6)$ \\
\hline & - Netherlands; same study: $[33,42]$ & $6 \%(2)$ \\
\hline & - Flanders (Belgium); same study: $[7,53]$ & $6 \%(2)$ \\
\hline & - Canada $[39,47]$ & $6 \%(2)$ \\
\hline & - Australia [36] & $3 \%(1)$ \\
\hline & - mixed (US and Netherlands) [30] & $3 \%(1)$ \\
\hline \multirow[t]{3}{*}{ Setting } & $\begin{array}{l}\text { - long-term care (mostly nursing homes) }[23,25,29,30,32,34,37,39-41,46,48,49-51] \text {; same } \\
\text { study: }[7,53] \text { and }[33,42]\end{array}$ & $58 \%(19)$ \\
\hline & $\begin{array}{l}\text { - community, including home care, ambulatory care clinics and GP settings [27, 31, 45, 47]; same } \\
\text { study: }[28,38]\end{array}$ & $18 \%(6)$ \\
\hline & $\begin{array}{l}\text { - mixed (due to sampling of physicians or families, no specific setting or sampling in more settings) } \\
{[35,36,43,44,52,54] ; \text { same study: }[13,24]}\end{array}$ & $24 \%(8)$ \\
\hline \multirow{5}{*}{$\begin{array}{l}\text { Study design (and mostly } \\
\text { analyses/reporting)* }\end{array}$} & Qualitative only, total & $64 \%(21)$ \\
\hline & - case study $[40,41,44,51]$ & $12 \%(4)$ \\
\hline & - other qualitative study $[23,25,27,30,32-34,39,42,43,45-47,49,50]$; same study: $[13,24]$ & $52 \%(17)$ \\
\hline & Quantitative only $[29,31,35,36,48,52,54]$; same study: $[7,53]$ and $[28,38]$ & $33 \%(11)$ \\
\hline & Mixed qualitative and quantitative [37] & $3 \%(1)$ \\
\hline \multirow[t]{3}{*}{$\begin{array}{l}\text { Factors (hypothesis) } \\
\text { pre-specified }\end{array}$} & $\begin{array}{l}\text { - explicit, pre-specified factors (the outcome is reported and allows for "no association;" } \\
\text { quantitative studies only) }[29,31,35,36,48,54] \text {; same study: }[7,53] \text { and }[28,38]\end{array}$ & $30 \%(10)$ \\
\hline & $\begin{array}{l}\text { - implicit testing of pre-specified factors (qualitative, quantitative, or case studies; may be } \\
\text { combined with explorative analyses as well) }[40,41,44,50,51] \text { or combined explicit and } \\
\text { implicit testing of factors }[13]^{\dagger}\end{array}$ & $18 \%(6)$ \\
\hline & $\begin{array}{l}\text { - none, because of a broad or explorative goal, no specific hypothesis }{ }^{\ddagger}[23-25,27,30,32,34,37 \text {, } \\
39,43,45-47,49,52] \text {; same study: }[33,42]\end{array}$ & $52 \%(17)$ \\
\hline \multirow[t]{5}{*}{ Perspectives } & - patient only [29]; same study: $[7,53]$ and $[28,38]$ & $15 \%(5)$ \\
\hline & - family caregiver only $[23,27,31,32,34,39,43,50,52] ;$ same study: $[13,24]$ & $33 \%(11)$ \\
\hline & $\begin{array}{l}\text { - professional caregiver only; physicians [30, 35, 36, 41, 45]; nurses [46]; nurse plus managers } \\
\text { [49]; chart only [54] }\end{array}$ & $24 \%(8)$ \\
\hline & - mixed family and other $[25,47,48,51]$ & $12 \%(4)$ \\
\hline & - observation of interaction between and within several parties [37, 40, 44]; same study: [33, 42] & $15 \%(5)$ \\
\hline \multirow[t]{3}{*}{ Dementia stage } & - mild, or mild to moderate [28 (subsample of [38]), 35] & $6 \%(2)$ \\
\hline & $\begin{array}{l}\text { - severe (or moderate to severe, but mostly exclusively severe, advanced, end-stage) }[7,23,25,29 \text {, } \\
32,34,37,39,40,44,48,50] \text {; same study: }[13,24]\end{array}$ & $42 \%(14)$ \\
\hline & - all stages or not specified [27, 30, 31, 36, 38, 41, 43, 45, 46, 47, 49, 51-54]; same study: [33, 42] & $52 \%(17)$ \\
\hline
\end{tabular}

${ }^{*}$ The data of one study may be published in more articles; ${ }^{\dagger}$ From this article [13], we report only on factors that related to an explorative goal, because the analyses of the qualitative, explorative study that also quantified associations with, for example, demographics, were underpowered; ${ }^{\ddagger}$ Goal is described in terms of "to describe the decision making process," "to describe palliative care practice," or "to explore views and experiences" (mostly qualitative studies, however, possible for quantitative studies that report on a large number of associations without statistical testing [52]).

found factors referring to structure and process of care, and the three parties involved: professional caregivers, patient, and family, and specified a number of sub cat- egories. Guidance, guidelines, and regulations were mentioned in articles from the UK only [41, 45, 49, 51], whereas a philosophy of comfort care came from 
Table 2

Pre-specified factors explicitly associated with initiating advance care planning

\begin{tabular}{|c|c|c|c|c|}
\hline \multirow[t]{2}{*}{ Perspective } & \multirow[t]{2}{*}{ Factor } & \multicolumn{3}{|c|}{ Initiating ACP (timing outcome) and association* } \\
\hline & & $\begin{array}{l}\text { Discussion } \\
\text { (a) }\end{array}$ & $\begin{array}{l}\text { Decision } \\
\text { Making } \\
\text { (b) }\end{array}$ & $\begin{array}{l}\text { Written advance } \\
\text { directive (c) }\end{array}$ \\
\hline Patient & $\begin{array}{l}\text { Health } \\
\text {-Comorbid disease: } \\
\text { depression } \\
\text { malignancy } \\
\text { cardiovascular, respiratory, urogenital, metabolic disorder, other } \\
\text { neurological disease } \\
\text { congestive heart failure } \\
\text {-Clinical deterioration } \\
\text { More severe dementia [38]; same study: } \\
\text { [7, 53] or perceived lack of decision making capacity [35] } \\
\text { History of dementia in family } * *\end{array}$ & $\downarrow[35]$ & $\begin{array}{l}\uparrow[54] \\
\uparrow[54]\end{array}$ & $\begin{array}{c}\uparrow^{? \dagger}[28] \\
\uparrow \quad[38] \\
=[29] ; \text { same study: }[7,53] \\
=\text { same study: } \\
{[7,53] \text { and }[28,38]} \\
\uparrow[29]^{\ddagger} \\
\uparrow[28]^{\uparrow}[29] \\
=[38]^{\uparrow} \\
\text { =same study: }[28,38] \\
\downarrow[29]^{\ddagger}\end{array}$ \\
\hline $\begin{array}{l}\text { Patient } \\
\text { Family }\end{array}$ & Ethnic minority & & $\downarrow[31]$ & $\downarrow[28,29]$ \\
\hline Family closeness & $\begin{array}{l}\text {-Living situation, had not lived with others } \\
\text {-Family not involved }\end{array}$ & $\downarrow[36]$ & & $\begin{array}{l}\downarrow[29]^{\ddagger} \\
\downarrow[7] \\
\downarrow=[53]^{\dagger \dagger}\end{array}$ \\
\hline $\begin{array}{l}\text { Physician } \\
\text { Health care system }\end{array}$ & $\begin{array}{l}\text { Lack of time** } \\
\text { ACP intervention** }\end{array}$ & $\begin{array}{l}\downarrow[35] \\
\uparrow[48]\end{array}$ & & \\
\hline Health care context & $\begin{array}{l}\text { Local factors, unspecified and unexplained variability between } \\
\text { facilities** }\end{array}$ & & & $\uparrow \downarrow[29]$ \\
\hline
\end{tabular}

*Direction of association, with = indicating no association, $\downarrow$ indicating a negative association with the outcome, which may be interpreted as a barrier, and $\uparrow$ a positive association with the outcome which may be interpreted as a facilitator (note that the reverse can be considered a barrier); ‘'?" means an uncertain association for the subgroups of those with mild cognitive impairment and mild or severe Alzheimer's disease as compared to cognitively intact; because of an interaction, age may be less important in the group with mild cognitive impairment and Alzheimer’s disease; ${ }^{\ddagger}$ Association significant in univariable analyses, not in multivariable analyses; "The same study had different findings. One of the studies better suited our research questions because of limiting to those with dementia [38] versus [28], and [7] versus [53], survival analyses referring to timing rather than binary logistic regression [38] versus [28], but variable definition for educational level with more categories was more informative in [28] versus [38]; ${ }^{\S}$ Significant association of dementia (severity) with having and advance directive, but not with a patient authorized legal representative. Same for neurological disease in this sample of patient with and without dementia [53]; ${ }^{* *}$ Included in this table on explicit pre-specified factors despite found in only one study ( 1 or 2 articles), because a similar factor was found in articles with no explicit pre-specified factors (Table 3); ${ }^{\dagger}$ No significant association of having involved family with having and advance directive, but significant for a patient authorized legal representative.

US work [25, 37], and continuity of care as a facilitator from Dutch-US comparative work [30]. The fewest number of factors related to process (continuity) of care, and the largest number to families. Family factors were identified from articles that included a family perspective or observation, and in only one article providing a (non)family (professional only) perspective [49]. Those most frequently identified (shaded cells in Table 3) were: patients' health, professional caregivers' and families' initiative, and families' wish or willingness to engage in ACP.

\section{Main factors: willingness or reluctance to engage in ACP, initiative, and patient's health}

A reluctance to engage in $\mathrm{ACP}$ and not taking initiative were barriers to initiating ACP found among all involved. Among patients and families, reluctance was also phrased as "unwillingness," "active avoidance," and "not being ready." Less outspoken was not feeling a need to engage into ACP (or "blind trust" or "passive avoidance"), which was close to not taking initiative. Some articles provided detail, enabling 
Table 3

Facilitators and barriers of initiating advance care planning which were not pre-specified (implicitly pre-specified or abstracted from explorative work)

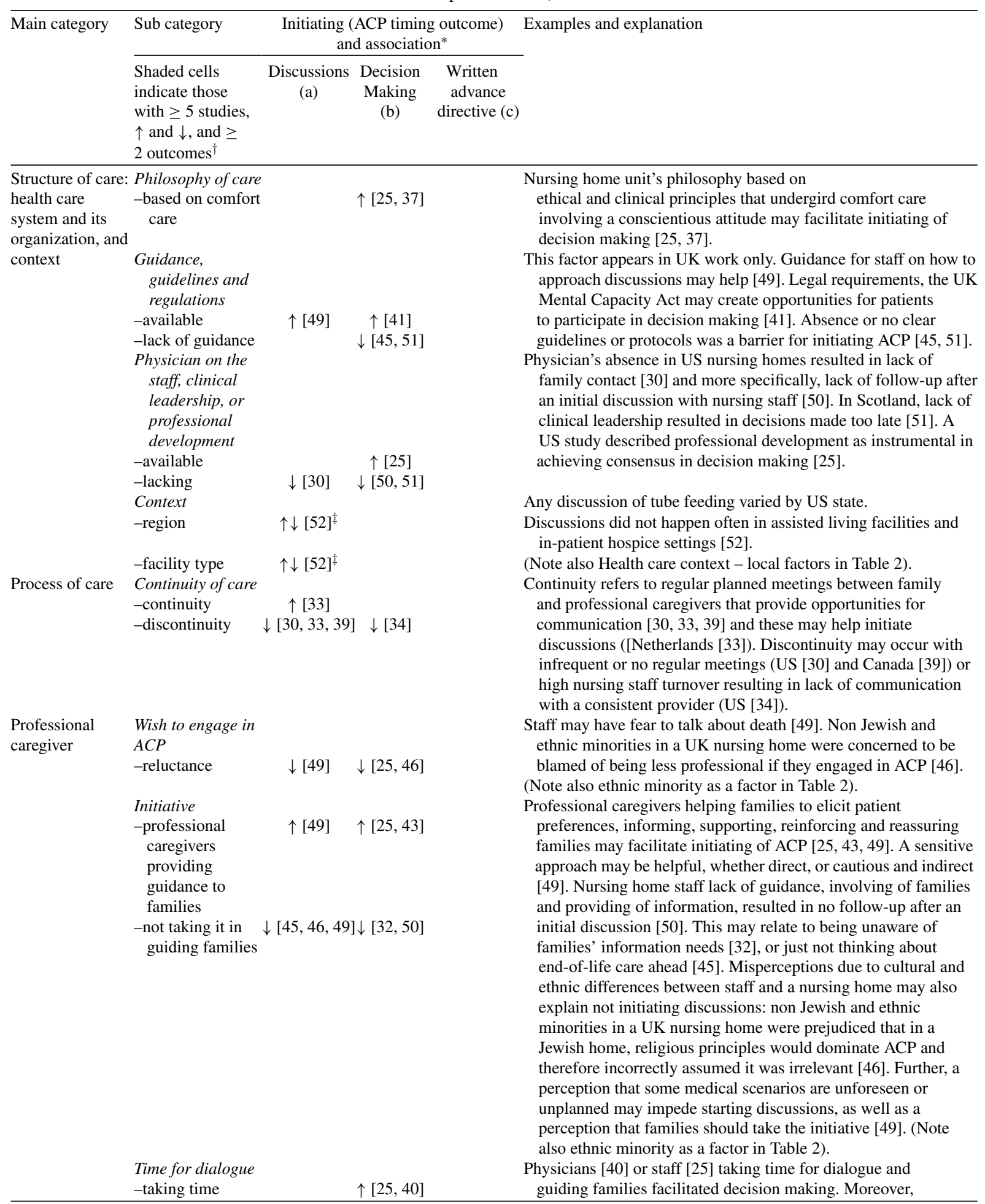


Table 3

(Continued)

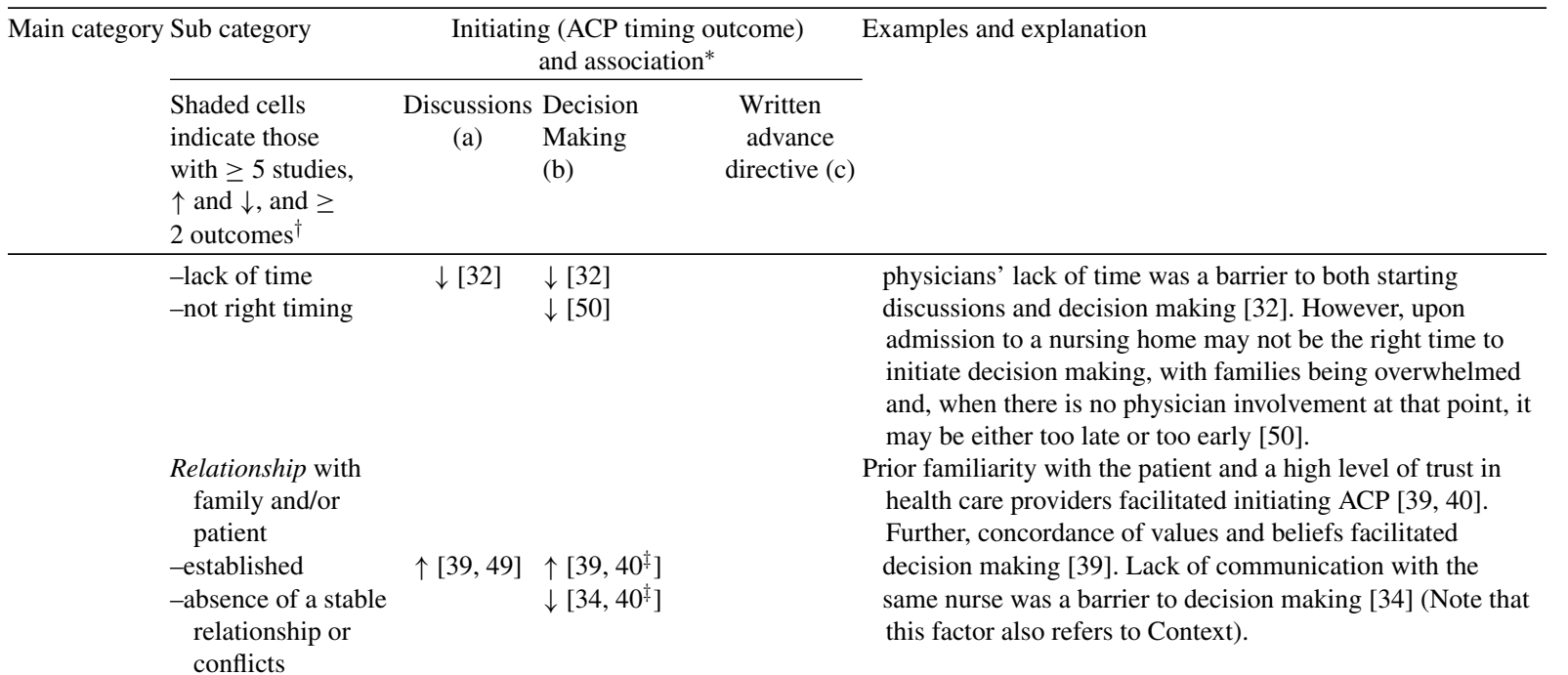

Patient Demographics

-older

Wish or willingness

to engage in $A C P$

-reluctance

- not feel a need

US patients with no discussion of tube feeding were older [52]. Patient's reluctance to engage in advance care planning and avoidance as perceived by family, was a barrier to starting discussions [23]; same study: [13, 24]. The reluctance may be specified as relating to patient's fear of death [23], discussion not being in the patient's personality, same study: [13, 24], and denial of dementia diagnosis or anything being wrong, same study $[13,24]$, which may or may not relate to coping strategies.

Initiative

-encouraged by

Family or others encouraging the patient may be essential to

others

Attitude of planning,

anticipating

-put things in order

-to live by the day

Experience

-motivated by "life

events"

Health condition

-decline

-health problem

-patient incapable

$\uparrow[24] \quad \uparrow[25,33,34$,

$\uparrow[52] \quad 37,40,42]$

of being involved

$[24,45,49]$

$$
37,40,42]
$$

Wishes

$$
\begin{aligned}
& \text {-expressed by } \\
& \text { patients } \\
& \text {-absence of clear } \\
& \text { wishes }
\end{aligned}
$$
start discussions and planning [23].

Patients may create document to ease decision making for their families [23], or may not plan ahead in general [23].

Patient decline in general may facilitate starting of decision making in the context of continuous availability of physicians or nurses involved in care planning with families [25, 33, 40, 42]. Further, families witnessing patient decline [23-25, 34, $37,42]$ including after a traumatic hospitalization [24, 37] or patients choking on food [52] related to initiating ACP. This is interpreted as a positive factor but can also be a negative in the absence of clinicians' guidance, such as families thinking about decisions only when forced by events [34], and the patient may no longer be capable of being involved in developing plans [23, 24, 45, 49]. Of note, patients' failing health may lead to the development of documents [23], but only when the family was emotionally prepared.

Absence of patient's wishes in writing and different views of family members may complicate the making of a decision [44], whereas patient's expressing of wishes, including in the family context [23] was helpful to initiate ACP $[23,27]$. 
Table 3

(Continued)

\begin{tabular}{|c|c|c|c|c|c|}
\hline \multirow{2}{*}{ Main category } & \multirow{2}{*}{$\begin{array}{l}\text { Sub category } \\
\text { Shaded cells } \\
\text { indicate those } \\
\text { with } \geq 5 \text { studies, } \\
\uparrow \text { and } \downarrow, \text { and } \geq \\
2 \text { outcomes }{ }^{\dagger}\end{array}$} & \multicolumn{3}{|c|}{$\begin{array}{l}\text { Initiating (ACP timing outcome) } \\
\text { and association* } \\
\end{array}$} & \multirow[t]{2}{*}{ Examples and explanation } \\
\hline & & $\begin{array}{l}\text { Discussions } \\
\text { (a) }\end{array}$ & $\begin{array}{l}\text { Decision } \\
\text { Making } \\
\text { (b) }\end{array}$ & $\begin{array}{l}\text { Written } \\
\text { advance } \\
\text { directive (c) }\end{array}$ & \\
\hline \multirow[t]{11}{*}{ Family } & $\begin{array}{l}\text { Demographics } \\
\text { - female } \\
\text { Education } \\
\text {-higher level } \\
\text {-lower level } \\
\text { Wish or willingness } \\
\quad \text { to engage in ACP } \\
\text {-reluctance } \\
\text {-not feel a need } \\
\text {-being emotional/ } \\
\text { coping }\end{array}$ & $\begin{array}{c}\downarrow[52] \\
\uparrow[52] \\
\downarrow[52] \\
\\
\downarrow[13,23,32] \\
\downarrow[23,24,39] \\
\downarrow[24,33]\end{array}$ & $\begin{array}{l}\quad \downarrow[32] \\
\quad \downarrow[34] \\
\quad \uparrow[25]{ }^{\ddagger} \\
\downarrow[25,34,43,49]\end{array}$ & $\downarrow[23]$ & $\begin{array}{l}\text { No discussion of tube feeding was more frequent if the } \\
\text { respondent (caregiver) was female [52]. } \\
\text { High school graduates more often had no discussion } \\
\text { of feeding tubes, whereas having no discussion was } \\
\text { less frequent among those with } 1-3 \text { years of college [52]. } \\
\text { There may be a reluctance to talk about the sensitive subject } \\
\text { of death and dying specifically, avoiding discussions with } \\
\text { staff [49] to not seem an advocate for death [32]. Another } \\
\text { study reported "blind trust" as a barrier to starting } \\
\text { discussions [39], or "passive avoidance" [24]. Staff may } \\
\text { help families prepare [25]. Some families may feel others, } \\
\text { or the disease impose the decisions [43]. A large } \\
\text { emotional burden and feeling guilty may be a barrier to } \\
\text { start decision making [25, 34, 43]. Family may deny that } \\
\text { the patient is at the end of life [49]. By contrast, they may } \\
\text { also have the psychological resources to cope with } \\
\text { outcomes of discussions [25]. }\end{array}$ \\
\hline & $\begin{array}{l}\text { Initiative } \\
\text {-professional } \\
\text { guidance }\end{array}$ & & $\uparrow[25,27,43]$ & & $\begin{array}{l}\text { Taking the initiative to start decision making also involves a } \\
\text { cognitive component along with information needs: } \\
\text { families may be unable to or need professional's help to }\end{array}$ \\
\hline & -not taking it & $\downarrow[32]$ & $\downarrow[25,27,32,34]$ & & $\begin{array}{l}\text { visualize possible disease trajectories }[25,34,43] \text { and to } \\
\text { familiarize with types of decisions or the decision making } \\
\text { process }[32,43] . \text { Providing of clear prognostic } \\
\text { information may help start decision making [27]. }\end{array}$ \\
\hline & $\begin{array}{l}\text { Attitude of planning, } \\
\text { anticipating }\end{array}$ & & & & $\begin{array}{l}\text { Family attitude of active planning may reflect a wish to put } \\
\text { things in order }[24,27,43] \text { and include the wish to }\end{array}$ \\
\hline & $\begin{array}{l}\text {-to put things in } \\
\text { order }\end{array}$ & & $\uparrow[24,27,43]$ & & $\begin{array}{l}\text { ease decision making for other family [27]. It involved } \\
\text { being pragmatic and realistic [43]. Others tended to take }\end{array}$ \\
\hline & -to live by the day & & $\downarrow[27,34,43]$ & & $\begin{array}{l}\text { one day at a time and felt more comfortable to postpone } \\
\text { decisions to "when the need arose" }[34,43] \text {, which } \\
\text { families may justify by the inability to look far in the } \\
\text { future }[27,43] \text {. }\end{array}$ \\
\hline & $\begin{array}{l}\text { Experience } \\
\text {-having witnessed } \\
\text { others }\end{array}$ & $\uparrow[23,24,27]$ & $\uparrow[34]$ & $\uparrow[23]$ & $\begin{array}{l}\text { Having witnessed other people with dementia }[27,34] \text { or } \\
\text { other people's illness or death }[23,24] \text { facilitated } \\
\text { initiating ACP. Such triggers may be medical, but may }\end{array}$ \\
\hline & $\begin{array}{l}\text {-awareness } \\
\text { vulnerability } \\
\text { patient increases } \\
\text { over time }\end{array}$ & & $\uparrow[47]$ & & $\begin{array}{l}\text { also refer to changes of the living situation or financial } \\
\text { issues of friends or other family [24]. One study found } \\
\text { that over time, families realise that the potential of a crisis } \\
\text { increases [47] and this would trigger tailored decision } \\
\text { making. }\end{array}$ \\
\hline & $\begin{array}{l}\text { Family dynamics } \\
\text { - conflicts, distrust } \\
\text { - advice }\end{array}$ & $\downarrow[23]$ & $\begin{array}{l}\downarrow[27,40,44] \\
\quad \uparrow[27]\end{array}$ & & $\begin{array}{l}\text { Family conflicts or disagreement may be a barrier to } \\
\text { consensus building [40,44] and therefore complicate } \\
\text { initiating the taking of decisions [27]. Distrust between } \\
\text { family and patient may impede starting discussions [23]. } \\
\text { On the other hand, consulting of other family members } \\
\text { may help start decision making [27]. }\end{array}$ \\
\hline & Involvement & & & & Family may be disengaged which needs staff action [25]. \\
\hline & -disengaged & & $\downarrow[25]$ & & Note also family closeness in Table 2. \\
\hline
\end{tabular}

${ }^{*}$ Direction of association, with $\downarrow$ indicating a barrier, and $\uparrow$ indicating a facilitator (note that, in view of more explorative goals, the reverse factor cannot necessarily be interpreted as a barrier or facilitator, respectively); ${ }^{\dagger}$ Shaded cells indicate factors identified most frequently: those reported in 5 or more studies, working as a barrier and the reciprocal as a facilitator, and for at least two of three outcomes; the same factor is shaded only for the party that meets these criteria (e.g., for "Wish to engage in ACP" the family only); ${ }^{\ddagger}$ Both directions possible as the factor was phrased neutrally referring to both directions. 
further interpretation of reluctance as fear of being blamed, or fear of death, feelings of guilt, personality, or denial which may or may not be explained in terms of coping [13, 23-25, 32, 34, 43, 46, 49]. The articles specified multiple reasons for not taking the initiative; for example, not having thought about it [45], misperceptions [46], being unclear about roles [49] for professionals, and for families, being unclear about possible disease trajectories and the process of decision making [25, 34, 43]. Further, there were individual differences in attitudes toward planning and anticipating in general, which affected initiating ACP in both patients and families.

Having a picture of the disease trajectory may help initiate ACP: families may have witnessed disease or death before, or visualize it when professionals inform families on this (Table 3). Otherwise, the family may witness the patient's decline and this may trigger ACP in a later phase. For example, one article reported that over time, families realize that the potential of a crisis increases [47] and this would trigger decision making. Family's witnessing a patient's decline was mostly perceived as a facilitator, but in the absence of clinicians' guidance, families may think about decisions only when forced by events [34].

Families' reluctance to engage in ACP discussions was reported along with patient's reluctance in two studies [23]; same study, one of which with two articles [13, 24]. Further, several articles [23, 32] pointed to the complexity of factors involved. For example, even for discussions between patient and family only, Black et al. [23] reported that initiating discussions and writing of advance directives may be hindered by a combination of the patient's or family's reluctance to discuss an unpleasant topic, lack of an easy opportunity to begin such a discussion, or a belief on the part of the family, patient or both that such a discussion was not necessary. This study also theorized that whether to discuss was driven by "intrinsic catalysts" such as the willingness of patient or family to discuss wishes as well as "extrinsic factors" such as encouragement by others and witnessing the end of life of someone else, and when exactly was driven more by such extrinsic factors. Further, patients' declining health led to the development of documents, but (interacted) only when the family was emotionally prepared [23].

\section{Common factors pre-specified and non pre-specified, and common to more groups}

Some factors reported in Table 3 were also tested directly as a pre-specified factor (Table 2), for exam- ple, $33 \%$ of physicians confirmed that lack of time was an issue in a survey study [35]. Some were found with other groups: family views elicited this factor too [32] (Table 3). A quantitative US study explored a large number of factors related to discussions and decisions about tube feeding at any time during a patient's life [52]. There was no statistical testing of associations and we considered this work not strongly hypotheses-driven. Some of the factors, however, were more similar to the pre-specified factors in Table 2, such as demographics and health problems. Further, the cultural and ethnic barriers reported in Table 2 were also identified in explorative work reported in Table 3 [46, 49], although in one of these articles [49] the authors seemed to challenge an implicit assumption that cultural beliefs related to difficulty discussing matters.

\section{Additional factors from single studies}

Most factors were reported in more studies and as such reported in the tables. We additionally identified a few single factors including waiting lists in Canada (health care system) forcing families to think ahead of desirability of hospitalization as an alternative to nursing home admission [47], staff consensus among themselves preparing for achieving consensus with family [25], and a son trying to protect a his mother from the discomfort of discussing the topic [23].

\section{Explicit qualification as too late}

Some articles reported on initiating ACP as having been "too late," for example when the patient was no longer capable of being involved due to progressed cognitive impairment [13, 23, 24, 35, 45, 49, 51] (Table 3). Families may express regret on having been too late to discuss ACP [13, 24] or having failed to anticipate problems in the dying phase [51].

\section{DISCUSSION}

In this systematic review, we identified 33 articles that reported on a variety of factors involved in initiating ACP. Family factors dominated, with family's initiative or lack of it, and willingness or reluctance identified in a series of studies. Further, professional caregivers' initiative or lack of it, and patient's health status were important factors that facilitated or hindered initiating ACP. We also found continuity of care and health care system factors affecting the initiation of the ACP process. 


\section{Generalizability}

The large majority of factors was found in multiple articles, which suggests that many factors generalize to different settings and countries. The factors were also consistent across the three initiating outcomes (discussions, decision making, and written advance directive) for the data available. Moreover, factors consistently pointed to the same direction, except for demographics.

We identified fewer patient factors, typically prespecified quantitative factors related to living wills or related to the patient's health probably because only a few articles examined patient views directly. Our finding that family factors dominated should be interpreted in view of the larger number of studies that presented family views, although most such studies also reported their views on encounters with professionals. The richest studies that provided the most factors were explorative, often qualitative work with no prespecified hypothesis, which also showed a complex interplay between more factors identified as associated with ACP. This suggests that at times, initiating ACP depends on factors that happen to optimally interplay in time, for example, with a professional initiating a discussion when the family and patient are receptive, feeling an urgency to start ACP before a crisis develops triggered by the patient experiencing a modest health decline.

Taking the initiative and time, and a positive attitude toward anticipating future scenarios seem universal across different parties and studies. Studies in dementia [6] and other palliative care populations found that discussion of end-of-life issues may often not take place or start too late $[55,56]$. The sensitivity and individuality of the subject may be reflected in the type of facilitators we identified; some, such as taking ample time to listen and professional and personal life experience with serious illness or death overlapped with facilitators of spiritual care giving $[57,58]$.

\section{Methodological considerations; limitations and strengths}

The nursing literature contributed substantially to our review; Cinahl identified 7 of the 8 articles not identified by PubMed. The review focused on timing and not on possible preceding factors such as recognizing dying or dementia as a disease you can die from [59], nor on the contents of ACP or the decisions taken or care delivered. It is conceivable that factors overlap, yet differ. For example, delivered care may be affected more strongly by the health care system including staffing and staff skills [51, 60], and decisions taken to forgo treatment may need more support from professionals compared with consent to treatment [61]. Similarly, factors associated with having an advance directive may differ from those associated with do-not-resuscitate orders [29].

We excluded hospital-based studies from our review assuming, based on early work, this environment suboptimal to initiate ACP. However, recent work from Sampson et al. using mixed-methods indicated a similar complexity of factors related to initiating ACP in a UK hospital [62, 63], additionally identifying a private room being unavailable in the hospital hindering initiation of ACP. Further, in this study, families and patients were keen to discuss end-of-life issues, even if they were reluctant to decide, did not continue planning, or needed more time to explore the patient's situation [62]. Therefore, future work should include the hospital setting. We included work with a minority of people with no dementia. From this work we learn that the dementia itself may be a barrier (to writing advance directives [53]) and that factors might differ somewhat from those in people who are not cognitively impaired $[7,28,53]$.

Abstracting of factors related to initiating ACP was not always straightforward; we therefore adopted a rigorous approach with abstracting of factors by more researchers independently. Some articles did not limit to end-of-life care but included discussion of, for example, legal and financial issues [27, 35, 43] which we could not always separate, nor did rich qualitative work always clearly distinguish factors related to initiating ACP and the contents of the decision [32, 33]. Other, quantitative, work [7, 53] was difficult to interpret for our purpose because it reported on associations with factors for which a temporal relation with initiating ACP as the outcome is unlikely such as an (un)expected death assessed afterwards and place of death. Some case studies were not very informative presenting few factors from a specific case or although much in line with our findings, discussed these in global terms, for example: "The process and pitfalls of consensus building will vary depending on the patient's clinical condition, the family dynamics, and the level of pre-existing trust or conflict in the physician-patient-family relationships" [40].

We did not systematically judge the quality of the articles. We did, however, consider quality when, for example, ignoring results from underpowered statis- 
tical analyses in otherwise qualitative work [13]. We note that possible bias may be highly relevant to an assessment of strength of associations but less so in our review which limited to a comprehensive listing of factors potentially related to initiating ACP.

\section{Future research}

Future work in this fast developing field may find strategies to attune initiating ACP to the receptiveness, knowledge, and attitudes of all involved, professionals, families, and also patients. The field may learn from, for example, shared-decision making strategies to involve patients and families as partners, the psychological literature on coping, and remaining hopeful $[64,65]$, breaking bad news and communication strategies more generally, death denial [66], and ethics considering autonomy and coercion. So far, only few intervention studies on effectiveness of ACP have been performed; reviews on articles published until early $2010[5,6]$ found only one that included (a majority of) people with dementia [67], but newer studies in dementia have been published since then [10, 48, 62]. Experimental work may manipulate, or at least describe the system-related factors we identified as associated to initiating ACP. It should also provide accounts of how the interventions are being received by all parties. Mixed-methods studies or studies employing a collaborative, local approach such as action research are rare so far, but might better accommodate attitudinal aspects and inform the development of suitable interventions [63]. Observational studies may quantify the factors identified in this review and also, for example, determine the prevalence of regret of not having initiated ACP versus those who found it too early and identify factors associated with a perception of untimely initiation of ACP. Patients' and nurses' perspectives and community settings are understudied. Some qualitative reports presenting patient's views were published recently although not necessarily comprising factors related to the initiation of ACP [68-70]. Reports from different countries, settings, and health care systems may be helpful, and may increase through the trend we observed of other countries than the US publishing work more recently, and these non-US studies also presenting with more awareness of contextual factors. This review may be repeated in a few years because of the rapidly increasing attention for the topic also from the research community, and the empty cells and breadth of factors in our main Table 3 indicating that data saturation has not been reached yet.

\section{Recommendations for practice: the right timing}

We listed factors related to initiating ACP as identified from empirical studies, but the timing in these studies is not necessarily the right timing to initiate ACP. The right timing may also be affected by multiple interrelated factors, among which individual receptiveness, but as this has hardly been tested or evaluated, there is little evidence regarding optimal timing. Several authors explicitly stated that the initiation of ACP may just need time [25, 33, 40, 43, 47, 49, 62]. For example, the oldest article in our review ([25]) provides a number of recommendations including to avoid pushing family or staff for a premature decision and to give a healing period after the admission. Time is also needed for professionals to develop a trusting relationship with the family. However, in this particular setting, because of the continuous presence of staff including physicians, staff had ample opportunity to postpone, as discussions could still "be held immediately if a patient crisis occurs" [25]. Other such recommendations may also apply in these favorable circumstances, such as to reinforce that family may change their mind, and assure families that staff will spent more time when the patient is dying to facilitate the decision making [25]. Dutch work in a nursing home setting with physicians on the staff also reported that decisions may be postponed purposefully to allow more time for the family [33]. ACP itself of course also needs time and may require continuous care. If discontinuous, one risks being too late to initiate ACP when waiting for the patient to decline or post-hospitalization, when a revisiting of previous plans seems more appropriate. A systematic review found that providing of oral information over multiple sessions was the most successful intervention to even promote advance directives among older adults [71]. Of course, optimal timing requires optimal communication, and studies in western dementia and palliative care populations have highlighted that patients and families commonly prefer a combined confrontational and reassuring approach when discussing diagnosis or palliative care $[18,72,73]$.

\section{CONCLUSION}

Professional caregivers should initiate ACP if appropriate in individual cases, and invest time in building up relationships so that strategies carefully consider timing and receptiveness, and are family- and patientcentered. They may need to encourage families and patients to talk, guide discussions and decision making $[25,27,32]$, visualize possible disease trajectories 
$[25,34,43]$, and familiarize families and patients with decision making [32, 43]. Professionals may assess families' coping strategies as a way to individualize their approach [25]. Different disciplines may be involved in different countries, mostly, although not limited to physicians and nurses; psychologists, social workers [20], and spiritual care staff [74] may (also) play a role. Finally, our mapping of factors affecting the initiation of ACP may also inform research on the effectiveness of interventions that address the complex dynamics of barriers and facilitators of initiating ACP, and provide evidence to optimize the timing of ACP.

\section{ACKNOWLEDGMENTS}

We thank René H.J. Otten, MSc, Medical Information Specialist at the Medical Library, VU University Amsterdam for his role in the development of the search strategy.

This study was supported by ZonMw The Netherlands Organisation for Health Research and Development, grant number 1151.0001, and by EURO IMPACT, European Intersectorial and Multidisciplinary Palliative Care Research Training, funded by the European Union Seventh Framework Programme (FP7/2007-2013, under grant agreement $\mathrm{n}^{\circ}$ [264697]).

Authors' disclosures available online (http://www.jalz.com/disclosures/view.php?id=2072).

Preliminary results were presented at the International Association of Gerontology and Geriatrics (IAGG) World Congress in Seoul, 23-27 June 2013.

An abstract of this work was published as: van der Steen JT, van Uden N, van Soest-Poortvliet MC, Hallie-Heierman M, Onwuteaka-Philipsen BD, Deliens L, de Boer M, Van den Block L, Hertogh CM, de Vet HC (2013) A systematic review of factors associated with initiating of advance care planning in dementia. J Nutr Health Aging 17 (Suppl 1), S440.

\section{SUPPLEMENTARY MATERIAL}

Supplementary material is available in the electronic version of this article: http://dx.doi.org/10.3233/JAD131967.

\section{REFERENCES}

[1] Gillick MR (2004) Advance care planning. N Engl J Med 350, 7-8.

[2] Gillick MR (2004) Adapting advance medical planning for the nursing home. J Palliat Med 7, 357-361.
[3] Teno JM, Lynn J (1996) Putting advance-care planning into action. $J$ Clin Ethics 7, 205-213.

[4] Teno JM (2003) Advance care planning for frail, older persons. In Geriatric Palliative Care. Morrison RS, Meier DE, Capello C, eds. New York, Oxford University Press, Inc., pp. 307-313.

[5] Robinson L, Dickinson C, Rousseau N, Beyer F, Clark A, Hughes J, Howel D, Exley C (2012) A systematic review of the effectiveness of advance care planning interventions for people with cognitive impairment and dementia. Age Ageing 41, 263-269.

[6] Dening KH, Jones L, Sampson EL (2011) Advance care planning for people with dementia: A review. Int Psychogeriatr 23, 1535-1551.

[7] Vandervoort A, van den Block L, van der Steen JT, Vander Stichele R, Bilsen J, Deliens L (2012) Advance directives and physicians' orders in nursing home residents with dementia in Flanders, Belgium: Prevalence and associated outcomes. Int Psychogeriatr 24, 1133-1143.

[8] Detering KM, Hancock AD, Reade MC, Silvester W (2010) The impact of advance care planning on end of life care in elderly patients: Randomised controlled trial. BMJ 340, c1345.

[9] Molloy DW, Guyatt GH, Russo R, Goeree R, O'Brien BJ, Bédard M, Willan A, Watson J, Patterson C, Harrison C, Standish T, Strang D, Darzins PJ, Smith S, Dubois S (2000) Systematic implementation of an advance directive program in nursing homes: A randomized controlled trial. JAMA 283, 1437-1444.

[10] Livingston G, Lewis-Holmes E, Pitfield C, Manela M, Chan D, Constant E, Jacobs H, Wills G, Carson N, Morris J (2013) Improving the end-of-life for people with dementia living in a care home: An intervention study. Int Psychogeriatr 11, 1849-1858.

[11] van der Steen JT, Radbruch L, Hertogh CMPM, de Boer ME, Hughes JC, Larkin P, Francke AL, Jünger S, Gove D, Firth P, Koopmans RTCM, Volicer L; on behalf of the European Association for Palliative Care (EAPC) (2014) White paper defining optimal palliative care in older people with dementia: A Delphi study and recommendations from the European Association for Palliative Care. Palliat Med 28(3), 197209.

[12] Colling KB (2000) A taxonomy of passive behaviors in people with Alzheimer's disease. J Nurs Scholarsh 32, 239-244.

[13] Hirschman KB, Kapo JM, Karlawish JH (2006) Why doesn't a family member of a person with advanced dementia use a substituted judgment when making a decision for that person? Am J Geriatr Psychiatry 14, 659-667.

[14] Ayalon L, Bachner YG, Dwolatzky T, Heinik J (2012) Preferences for end-of-life treatment: Concordance between older adults with dementia or mild cognitive impairment and their spouses. Int Psychogeriatr 24, 1798-1804.

[15] Dunn LB, Fisher SR, Hantke M, Appelbaum PS, Dohan D, Young JP, Roberts LW (2013) "Thinking about it for somebody else": Alzheimer's disease research and proxy decision makers' translation of ethical principles into practice. Am J Geriatr Psychiatry 21, 337-345.

[16] van der Steen JT, Heymans MW, Steyerberg EW, Kruse RL, Mehr DR (2011) The difficulty of predicting mortality in nursing home residents. Eur Geriatr Med 2, 79-81.

[17] Wald C, Fahy M, Walker Z, Livingston G (2003) What to tell dementia caregivers-the rule of threes. Int J Geriatr Psychiatry 18, 313-317.

[18] Byszewski AM, Molnar FJ, Aminzadeh F, Eisner M, Gardezi F, Bassett R (2007) Dementia diagnosis disclosure: A study 
of patient and caregiver perspectives. Alzheimer Dis Assoc Disord 21, 107-114.

[19] de Boer ME, Droes RM, Jonker C, Eefsting JA, Hertogh CM (2012) Thoughts on the future: The perspectives of elderly people with early-stage Alzheimer's disease and the implications for advance care planning. AJOB 3, 14-22.

[20] van der Steen JT, Arcand M, Toscani F, de Graas T, Finetti S, Beaulieu M, Brazil K, Nakanishi M, Nakashima T, Knol DL, Hertogh CM (2012) A family booklet about comfort care in advanced dementia: Three-country evaluation. J Am Med Dir Assoc 13, 368-375.

[21] Teno JM, Licks S, Lynn J, Wenger N, Connors AF Jr, Phillips RS, O'Connor MA, Murphy DP, Fulkerson WJ, Desbiens N, Knaus WA (1997) Do advance directives provide instructions that direct care? SUPPORT Investigators. Study to Understand Prognoses and Preferences for Outcomes and Risks of Treatment. J Am Geriatr Soc 45, 508-512.

[22] Ahronheim JC, Morrison RS, Morris J, Baskin S, Meier DE (2000) Palliative care in advanced dementia: A randomized controlled trial and descriptive analysis. J Palliat Med 3, 265273.

[23] Black BS, Fogarty LA, Phillips H, Finucane T, Loreck DJ, Baker A, Blass DM, Rabins PV (2009) Surrogate decision makers' understanding of dementia patients' prior wishes for end-of-life care. J Aging Health 21, 627-650.

[24] Hirschman KB, Kapo JM, Karlawish JH (2008) Identifying the factors that facilitate or hinder advance planning by persons with dementia. Alzheimer Dis Assoc Disord 22, 293298.

[25] Hurley AC, Volicer L, Rempusheski VF, Fry ST (1995) Reaching consensus: The process of recommending treatment decisions for Alzheimer's patients. ANS Adv Nurs Sci 18, 33-43.

[26] Frahm KA, Brown LM, Hyer K (2013) (2012) Racial disparities in end-of-life planning and services for deceased nursing home residents. J Am Med Dir Assoc 13, 819.e7-11. Erratum in: J Am Med Dir Assoc 14, 625.

[27] Livingston G, Leavey G, Manela M, Livingston D, Rait G, Sampson E, Bavishi S, Shahriyarmolki K, Cooper C (2010) Making decisions for people with dementia who lack capacity: Qualitative study of family carers in UK. BMJ 341, c4184.

[28] Lingler JH, Hirschman KB, Garand L, Dew MA, Becker JT, Schulz R, Dekosky ST (2008) Frequency and correlates of advance planning among cognitively impaired older adults. Am J Geriatr Psychiatry 16, 643-649.

[29] Triplett P, Black BS, Phillips H, Richardson Fahrendorf S, Schwartz J, Angelino AF, Anderson D, Rabins PV (2008) Content of advance directives for individuals with advanced dementia. J Aging Health 20, 583-596.

[30] Helton MR, van der Steen JT, Daaleman TP, Gamble GR, Ribbe MW (2006) A cross-cultural study of physician treatment decisions for demented nursing home patients who develop pneumonia. Ann Fam Med 4, 221-227.

[31] Owen JE, Goode KT, Haley WE (2001) End of life care and reactions to death in African-American and white family caregivers of relatives with Alzheimer's disease. Omega (Westport) 43, 349-361.

[32] Gessert CE, Forbes S, Bern-Klug M (2000) Planning endof-life care for patients with dementia: Roles of families and health professionals. Omega (Westport) 42, 273-291.

[33] The AM, Pasman R, Onwuteaka-Philipsen B, Ribbe M, van der Wal G (2002) Withholding the artificial administration of fluids and food from elderly patients with dementia: Ethnographic study. BMJ 325, 1326.
[34] Forbes S, Bern-Klug M, Gessert C (2000) End-of-life decision making for nursing home residents with dementia. $J$ Nurs Scholarsh 32, 251-258.

[35] Cavalieri TA, Latif W, Ciesielski J, Ciervo CA Jr, Forman LJ (2002) How physicians approach advance care planning in patients with mild to moderate Alzheimer's disease. $J$ Am Osteopath Assoc 102, 541-544.

[36] Waddell C, Clarnette RM, Smith M, Oldham L (1997) Advance directives affecting medical treatment choices. J Palliat Care 13, 5-8.

[37] Powers BA, Watson NM (2008) Meaning and practice of palliative care for nursing home residents with dementia at end of life. Am J Alzheimers Dis Other Demen 23, 319-325.

[38] Garand L, Dew MA, Lingler JH, DeKosky ST (2011) Incidence and predictors of advance care planning among persons with cognitive impairment. Am J Geriatr Psychiatry 19, 712720 .

[39] Caron CD, Griffith J, Arcand M (2005) Decision making at the end of life in dementia: How family caregivers perceive their interactions with health care providers in long-term-care settings. J Appl Gerontol 24, 231-247.

[40] Karlawish JH, Quill T, Meier DE (1999) A consensusbased approach to providing palliative care to patients who lack decision-making capacity. ACP-ASIM End-of-Life Care Consensus Panel. American College of PhysiciansAmerican Society of Internal Medicine. Ann Intern Med 130, 835-840.

[41] Evans G (2009) Improving end of life care for the person with dementia: A practical approach from general practice. Dementia 8, 363-376.

[42] Pasman HRW, The BAM, Onwuteaka-Philipsen BD, Ribbe MW, van der Wal G (2004) Participants in the decision making on artificial nutrition and hydration to demented nursing home patients: A qualitative study. J Aging Studies 18, 321335.

[43] Wackerbarth S (1999) Modeling a dynamic decision process: Supporting the decisions of caregivers of family members with dementia. Qual Health Res 9, 294-314.

[44] Robinson EM, Kennedy-Schwarz J (2001) Caring for incompetent patients and their surrogates. Am J Nurs 101, 75-76.

[45] Grisaffi K, Robinson L (2010) Timing of end of life care in dementia; difficulties and dilemmas for GPs. J Dement Care 18, 36-39.

[46] Livingston G, Pitfield C, Morris J, Manela M, Lewis-Holmes E, Jacobs H (2012) Care at the end of life for people with dementia living in a care home: A qualitative study of staff experience and attitudes. Int J Geriatr Psychiatry 27, 643-650.

[47] St-Amant O, Ward-Griffin C, DeForge RT, Oudshoorn A, McWilliam C, Forbes D, Kloseck M, Hall J (2012) Making care decisions in home-based dementia care: Why context matters. Can J Aging 31, 423-434.

[48] Hanson LC, Carey TS, Caprio AJ, Lee TJ, Ersek M, Garrett J, Jackman A, Gilliam R, Wessell K, Mitchell SL (2011) Improving decision-making for feeding options in advanced dementia: A randomized, controlled trial. J Am Geriatr Soc 59, 2009-2016.

[49] Stewart F, Goddard C, Schiff R, Hall S (2011) Advanced care planning in care homes for older people: A qualitative study of the views of care staff and families. Age Ageing 40, 330-335.

[50] Givens JL, Selby K, Goldfeld KS, Mitchell SL (2012) Hospital transfers of nursing home residents with advanced dementia. J Am Geriatr Soc 60, 905-909.

[51] Reid L, Snowden A, Kydd A (2012) An exploration of palliative care provision in Scottish care homes. Br J Nurs 21 , 8-10, 12-15. 
[52] Teno JM, Mitchell SL, Kuo SK, Gozalo PL, Rhodes RL, Lima JC, Mor V (2011) Decision-making and outcomes of feeding tube insertion: A five-state study. J Am Geriatr Soc 59, 881886.

[53] De Gendt C, Bilsen J, Stichele RV, Deliens L (2013) Advance care planning and dying in nursing homes in Flanders, Belgium: A nationwide survey. J Pain Symptom Manage 45, 223-234

[54] Haydar ZR, Lowe AJ, Kahveci KL, Weatherford W, Finucane $T$ (2004) Differences in end-of-life preferences between congestive heart failure and dementia in a medical house calls program. J Am Geriatr Soc 52, 736-740.

[55] Abarshi E, Echteld M, Donker G, Van den Block L, Onwuteaka-Philipsen B, Deliens L (2011) Discussing endof-life issues in the last months of life: A nationwide study among general practitioners. J Palliat Med 14, 323330.

[56] Slort W, Schweitzer BP, Blankenstein AH, Abarshi EA, Riphagen II, Echteld MA, Aaronson NK, van der Horst H, Deliens L (2011) Perceived barriers and facilitators for general practitioner-patient communication in palliative care: A systematic review. Palliat Med 25, 613-629.

[57] Daaleman TP, Usher BM, Williams SW, Rawlings J, Hanson LC (2008) An exploratory study of spiritual care at the end of life. Ann Fam Med 6, 406-411.

[58] Edwards A, Pang N, Shiu V, Chan C (2010) The understanding of spirituality and the potential role of spiritual care in end-oflife and palliative care: A meta-study of qualitative research. Palliat Med 24, 753-770.

[59] van der Steen JT, Onwuteaka-Philipsen BD, Knol DL, Ribbe MW, Deliens L (2013) Caregivers' understanding of dementia predicts patients' comfort at death: A prospective observational study. BMC Med 11, 105.

[60] Carlson MD, Lim B, Meier DE (2011) Strategies and innovative models for delivering palliative care in nursing homes. J Am Med Dir Assoc 12, 91-98.

[61] Mezey M, Kluger M, Maislin G, Mittelman M (1996) Lifesustaining treatment decisions by spouses of patients with Alzheimer's disease. J Am Geriatr Soc 44, 144-150.

[62] Sampson EL, Jones L, Thuné-Boyle IC, Kukkastenvehmas R, King M, Leurent B, Tookman A, Blanchard MR (2011) Palliative assessment and advance care planning in severe dementia: An exploratory randomized controlled trial of a complex intervention. Palliat Med 25, 197-209.
[63] Sampson EL, Thuné-Boyle I, Kukkastenvehmas R, Jones L, Tookman A, King M, Blanchard MR (2008) Palliative care in advanced dementia; A mixed methods approach for the development of a complex intervention. BMC Palliat Care $7,8$.

[64] Wolverson Radbourne EL, Clarke C, Moniz-Cook E (2010) Remaining hopeful in early-stage dementia: A qualitative study. Aging Ment Health 14, 450-460.

[65] Robinson CA (2012) "Our best hope is a cure." Hope in the context of advance care planning. Palliat Support Care 10, 75-82.

[66] Zimmermann C (2007) Death denial: Obstacle or instrument for palliative care? An analysis of clinical literature. Sociol Health Illn 29, 297-314.

[67] Caplan GA, Meller A, Squires B, Chan S, Willett W (2006) Advance care planning and hospital in the nursing home. Age Ageing 35, 581-585.

[68] Poppe M, Burleigh S, Banerjee S (2013) Qualitative evaluation of advanced care planning in early dementia (ACP-ED). PLoS One 8, e60412.

[69] Dening KH, Jones L, Sampson EL (2013) Preferences for endof-life care: A nominal group study of people with dementia and their family carers. Palliat Med 27, 409-417.

[70] Goodman C, Amador S, Elmore N, Machen I, Mathie E (2013) Preferences and priorities for ongoing and end-of-life care: A qualitative study of older people with dementia resident in care homes. Int J Nurs Stud 12, 1639-1647.

[71] Bravo G, Dubois MF, Wagneur B (2008) Assessing the effectiveness of interventions to promote advance directives among older adults: A systematic review and multi-level analysis. Soc Sci Med 67, 1122-1132.

[72] van Vliet LM, van der Wall E, Plum NM, Bensing JM (2013) Explicit prognostic information and reassurance about nonabandonment when entering palliative breast cancer care: Findings from a scripted video-vignette study. J Clin Oncol 31, 3242-3249.

[73] Laakkonen ML, Raivio MM, Eloniemi-Sulkava U, Saarenheimo M, Pietilä M, Tilvis RS, Pitkälä KH (2008) How do elderly spouse care givers of people with Alzheimer disease experience the disclosure of dementia diagnosis and subsequent care? J Med Ethics 34, 427-430.

[74] Bailey FA, Allen RS, Williams BR, Goode PS, Granstaff S, Redden DT, Burgio KL (2012) Do-not-resuscitate orders in the last days of life. J Palliat Med 15, 751-759. 